\title{
The Relationship between Socioeconomic Status and Beliefs about Language Learning: A Study of Iranian Postgraduate EAP Students
}

\author{
Mohsen Ghasemi Ariani ${ }^{1,2} \&$ Narjes Ghafournia ${ }^{2}$ \\ ${ }^{1}$ Department of English, Khorasane Razavi Science and Research Branch, Islamic Azad University, Neyshabur, \\ Iran \\ 2 Department of English, Neyshabur Branch, Islamic Azad University, Neyshabur, Iran \\ Correspondence: Narjes Ghafournia, Department of English, Neyshabur Branch, Islamic Azad University, \\ Neyshabur, Iran. Tel: 98-915-313-0060. E-mail: narjesghafournia@yahoo.com; na.ghafournia@gmail.com
}

Received: June 26, 2015 Accepted: August 8, 2015 Online Published: August 11, 2015

doi:10.5539/elt.v8n9p17 URL: http://dx.doi.org/10.5539/elt.v8n9p17

\begin{abstract}
This study explored the probable interaction between Iranian language students' beliefs about language learning and their socio-economic status. To this end, 350 postgraduate students, doing English courses at Islamic Azad University of Neyshabur participated in this study. They were grouped in terms of their socio-economic status. They answered a questionnaire in which they indicated their beliefs about language learning in different contexts of language use. The quantitative data were subjected to a set of parametric statistical analyses, including descriptive statistics. The findings manifested a positive relationship between the participants' economic status and their beliefs about language learning. The findings reflected that social factors exert substantial influence on the process of language learning and language teachers should be highly qualified to make professional judgment about the actual language ability of language learners to decrease error of measurement. Language teachers should also create pleasant learning environment fostering learners' positive attitude toward language learning.
\end{abstract}

Keywords: language-learning belief, socio-economic status, measurement error

\section{Introduction}

Beliefs are main basis in the disciplines dealing with human learning and behavior (Ajzen, 1988; Fishbein \& Ajzen, 1975). In the educational context, beliefs and attitudes that students bring to the learning areas have been recognized as significant factors in the learning process (Breen, 2001). As an example, foreign/second language learners may have strong beliefs about the nature of the language under study, the process of language acquisition, language learning difficulties, their aptitude, effective use of certain learning strategies along with effective teaching methodologies and their particular learning needs. Identification of these beliefs and their reflection on language learning can enhance pedagogical practices and syllabus design in language courses (Arnold, 1999; Breen, 2001). In fact, successful learners pay serious attention to beliefs about language learning processes, experiences, expectations, and attitudes toward learning (Altan, 2012; Benson, 2001; Cotterall, 1995; Dörnyei, 2005; Horwitz, 2007; Nyikos \& Oxford, 1993; Rad, 2010; Sakui \& Gaies, 1999). Horwitz (2007) considered learners' beliefs about foreign language as central principle in each experience dealing with human behavior. Altan (2012) believed that at least some knowledge of English is urgent to make progress in life and work due to providing high social status and job opportunities for individuals. According to Rad (2010) and Dörnyei (2005), beliefs and attitudes of learners about foreign languages are fundamental and in the focus of educational progress. On the other hand, socio-economic status does not only have an influence on final language learning but also it affects learners' self-related beliefs and motivation to learn (Fan, 2011).Socio-economic factors can have a strong influence on learning. The study of Fonseka (2003) demonstrates the views of learners about what learning is and the roles learners should take in educational areas, which can affect their behavior and learning process. Benson (2007) also believed that economic factors can pave the way for learning and teaching.

According to Parson, Hinson and Sardo-Brown (2001), "Socio-economic Status (SES) is the term used to distinguish between people's relative position in the society in terms of family income, educational background and occupational prestige". SES is often described by social classes or groups internationally as defined by Socio-economic classification. These social classes are divided into five categories, such as "upper class", 
"upper middle class", "middle class", "lower middle class" and "lower class". There are some variations in class structure, but most of the time the mentioned five class structure is used. Socio-economic status has exerted a deep impact on language learning motivation and beliefs about learning processes (Mantle-Bromley, 1995). In fact, the seemingly stronger link between motivational factors, learner's beliefs, and socio-economic status might be due to the highly segregated nature of education and the deep socio-economic division among the investigated learners (Lamb, 2012). Although higher socio-economic learners have different choices to receive a high quality learning process, lower socio-economic learners deal with some difficulties to do so without having enough capital (Dong, 2011; Hannum, Park, \& Butler, 2010). Therefore, teachers need to respect their students' beliefs and perceptions and help them overcome any harmful attitudes, which block their learning process (Carr \& Pauwels, 2006; Gayton, 2010; Mantle-Bromley, 1995; Nikitina \& Furuoka, 2006). Besides, language teachers should enhance their students' awareness of their strengths and weaknesses as well as their strategic knowledge to facilitate their learning process (Mantle-Bromley, 1995; Peacock, 2001).

\section{Review of the Related Literature}

The idea that students' beliefs about foreign language learning have an influence on their success or failure in achieving competence in a foreign language is well documented (Horwitz, 1988; Jernigan, 2001; Kern, 1995; Miele, 1982; Rifkin, 2000; Strevens, 1978). The major findings of the above-mentioned studies indicate that individuals' positive or negative beliefs and perceptions about foreign language learning have a similarly positive or negative effect on their success. Mantle-Bromley (1995), for example, argued that positive beliefs about foreign language learning in relation to a positive learning environment such as trust-building between teachers and students can facilitate foreign language learning. Horwitz (1987) argued that students' beliefs about foreign language learning affect the types of learning strategies that these students choose. Besides, he contended that teachers cannot afford to ignore their students' beliefs if they wish to implement teaching methods that are efficient and well-received. Students' beliefs, like students' perception, have been commonly associated with beliefs of their own learning situation such as socio-economic status. Majoribanks (1996) explained the importance of SES not only in students' life but also in their learning environments. In studying the impact of various factors on students' learning, he concluded that the determining factor is SES. Socio-economic status is an important variable, which may affect first language and second language learning. Since Coleman's (1966) landmark study on Equality of Educational Opportunity, socio-economic status has been considered as a strong predictor of students' learning. Coleman asserted that the influence of students' background was greater than anything that goes on within learning. As such, socio-economic status as a main component is tied with students' beliefs. That is, students can focus on more external targets. Barcelos and Kalaja (2003) suggested that beliefs comprise "students' opinions and ideas about the task of learning a second or foreign language" (Barcelos \& Kalaja, 2003).

Although the literature has addressed the need to link socioeconomic factors with foreign language learning (e.g. Babikkoi \& Binti Abdul Razak, 2014; Demmert, 1993; Kormose \& Kiddle, 2013; Pennycook, 1994; Strevens, 1978; Turner, 1974), much of the research to date has focused on the case studies that highlight individual social circumstances in foreign language learning mainly in beginning classroom contexts (Graham \& Brown, 1996; Martin, 1990; Norton \& Toohey, 2001).

Therefore, the purpose of this study is to gain a better understanding of the factors that enhance or weaken language learning processes. Language learners' beliefs are serious components that constitute part of a large whole, called socio economic status. In fact, socio economic status and language learners' beliefs can have a mutual relationship, in which one thing affects another. Moe specifically, the research question is formulated as the following:

Is there any significant relationship between language learners' beliefs about language learning and their socio-economic status?

To probe the research questions, the method as well as findings is discussed in the following sections.

\section{Methodology}

\subsection{Participants}

The participants for this study were 350 Iranian postgraduate students of Management, doing English courses at Islamic Azad University in Neyshabur. Table 3.1 displays the descriptive statistics on background variables for the students whose questionnaires were used for analysis. As can be seen in Table 3.1, 54\% of the sample was males and $46 \%$ was females. In general, students ranged in age from 24 to 45 . But $13.42 \%$ were under 24 , $66.85 \%$ were young adults (24-35), and $19.73 \%$ were mature adult (35-45). The participants studied in six different interrelated sub-disciplines of management, including Insurance Management, Tourism Management, International Management, Financial Management, Marketing Management, and Internal Business Management. 
Participants were distributed across five social and economic groups.

Table 1. Frequency and percentage of the background information for the postgraduate participants

\begin{tabular}{lll}
\hline Gender & Percentage & Frequency \\
\hline Male & $52.8 \%$ & 204 \\
Female & $41.72 \%$ & 146 \\
Age & & \\
Under 24 & $13.42 \%$ & 47 \\
$24-35$ & $66.85 \%$ & 234 \\
$35-45$ & $19.73 \%$ & 69 \\
Disciplines & & \\
Insurance Management & $16.86 \%$ & 59 \\
Tourism Management & $19.14 \%$ & 67 \\
International Management & $12 \%$ & 42 \\
Financial Management & $18 \%$ & 63 \\
Marketing Management & $16.28 \%$ & 57 \\
Internal Business Management & $17.72 \%$ & 62 \\
Social and Economic Groups & & \\
Upper Class & $7.14 \%$ & 25 \\
Upper Middle Class & $20 \%$ & 70 \\
Middle Class & $30.86 \%$ & 108 \\
Lower Middle Class & $30 \%$ & 105 \\
Lower Class & $12 \%$ & 42 \\
Occupation & & 87 \\
Unemployed & $24.85 \%$ & 263 \\
Employed & $75.15 \%$ & \\
\hline
\end{tabular}

The table indicates that students ranged in age from 24 to 45 . But $13.42 \%$ were under $24,66.85 \%$ were young adults (24-35), and $19.73 \%$ were mature adult (35-45). In general, $54 \%$ of the sample was males, and $46 \%$ was females. The participants were categorized in six sub-disciplines of management, including Insurance Management (16.86\%), Tourism Management (19.14\%), International Management (12), Financial Management (18\%), Marketing Management (16.28\%), and Internal Business Management (12\%). They were distributed across upper class (7.14\%), upper middle class (20\%), middle class (30.86), lower middle class $(30 \%)$, and lower class (12\%). Occupational categories show that $24.85 \%$ of the students were unemployed and $75.15 \%$ were employed.

\subsection{Instruments}

The instrument was developed in two stages. In the first stage, many items were derived from existing instruments such as the Belief Inventory, developed by Horwitz (BALLI, 1988). In the second stage, in order to elicit some particular information about the participants' social and economic data, a Socio-economic Status (SES) Questionnaire was used. In fact, it was constructed and reviewed by different experts of Psychology, Sociology and Languages, who gave their feedback on the content.

3.2.1 The Beliefs about Language Learning Inventory (BALLI)

The questionnaire that was derived from Horwitz' (1987) 35-item Beliefs about Language Learning Inventory (BALLI) was utilized in this study. The questionnaire is a five-point Likert scale, ranging from 1 (strongly disagree) to 5 (strongly agree) options containing 33 items. The participants had to rate the statements on their beliefs about language learning. Beliefs about Language Learning Inventory (BALLI) explores five logical areas, i.e., beliefs dealing with foreign language aptitude (items 1, 2, 5, 6, 10, 11, 16, 19, 30, 33, 35) learning and 
communication strategies (item $9,13,14,17,18,21,22,26$ ), the nature of language learning (items $8,12,17$, $23,27,28$ ), difficulty involved in learning (items $3,4,15,25,34$ ) and motivations and expectations (items 20 , 24, 29, 31, 32). To remove probable ambiguities, the BALLI questionnaire was translated into Persian, the participants' mother tongue. Before the actual administrations, the BALLI and SES questionnaire were checked by some professors on language, who gave useful feedback on the content of the questionnaire as well as the clarity of the items. Then, BALLI piloted on a sample of about 25 students, whose feedback improved the items.

\subsubsection{SES Questionnaire}

"Socio-economic Status (SES) Scale Questionnaire" was used to identify the Socio-economic Status (SES) of the sampled students. It was reviewed by different experts of languages, who gave their feedback on the content. In the light of the experts' opinions, the instruments were finalized. It piloted on a sample of about 25 students to improve the items. The reliability analysis showed an overall Alpha Cronbach's value of .850.

\subsection{Procedure}

The data was provided by 350 postgraduate students, doing English courses at Islamic Azad University of Neyshabur. They answered two questionnaires, in which they measured learners' beliefs about language learning and their socio-economics statuses.

\subsection{Data Analysis}

The statistical procedures used in the study were Cronbach alpha formula, principal component analysis, and descriptive statistics.

\section{Result and Discussion}

\subsection{Latent Variables Explored by the BALLI}

In order to enhance the reliability of the results, a principal component analysis of the data was carried out. Table 2 summarizes the results of the principal component analysis of the data gathered in this study as well as Horwitz's (1987) separation of items under her five themes.

\subsubsection{Foreign Language Aptitude}

According to Horwitz's (1987) grouping of inventory items, eleven separate variables (items 1, 2, 5, 6, 10, 11, $16,19,30,33,35)$ were linked to the theme of foreign language aptitude.

\subsubsection{Difficulty of Language Learning}

Originally, five items (Items 3, 4, 15, 26, 35) were listed under the theme of difficulty of language learning.

4.1.3 Nature of Language Learning.

The third component is a collection of variables (items $8,12,17,23,27,28$ ) initially listed under the theme of nature of language learning.

\subsubsection{Learning and Communication Strategies}

Horwitz's (1987) learning and communication strategies theme consisted of eight items (items 9, 13, 14, 17, 18, 21, 22, and 26).

\subsubsection{Motivation and Expectations}

The five original items in the theme of motivation and expectations (items 20, 24, 29, 31, 32) were supplemented by an item inquiring about respondents' hopes of making friends with non-native English. The motivation component consisted of the items dealing with both integrative and instrumental motivation (Dörnyei, 1990; Kormos \& Csizér, 2008). Table 2 indicates the questionnaire items as well as factor analysis loadings.

Table 2. Horwitz's (1987) Separation of BALLI Items

\begin{tabular}{lc}
\hline Beliefs & Loading \\
\hline Factor 1. Foreign language aptitude (Cronbach's alpha =.80) & 0.63 \\
1. It is easier for children than adults to learn a foreign language & 0.62 \\
2. Some people have a special ability for learning foreign languages. & 0.59 \\
5. I believe that I will learn to speak English very well & 0.57 \\
6. People from my country are good at learning foreign languages. & 0.57 \\
10. It is easier for someone who already speaks a foreign language to learn another one. & 0.55 \\
30. People who speak more than one language are very intelligent & \\
\hline
\end{tabular}




\begin{tabular}{lr}
\hline 33. Everyone can learn to speak a foreign language. & 0.55 \\
35. Language learning involves a lot of memorization. & 0.49 \\
11. People who are good at mathematics or science are not good at learning foreign languages. & 0.49 \\
16. I have a special ability for learning foreign languages & \\
19. Women are better than men at learning foreign languages. & 0.47 \\
& 0.46
\end{tabular}

Factor 2: difficulty of language learning (Cronbach's alpha $=.86)$

3. Some languages are easier to learn than others.

4. English is a difficult/easy language.

15. If someone spent one hour a day learning a language, how long would it take them tospeak the 0.60 language very well?

25. It is easier to speak than understand a foreign language.

34. It is easier to read and write English than to speak and understand it.

Factor 3: Nature of language learning (Cronbach's alpha $=.84)$

8. It is important to know about English-speaking cultures in order to speak English

12. It is best to learn English in an English-speaking country.

17. The most important part of learning a foreign language is learning vocabulary words

23. The most important part of learning a foreign language is learning the grammar

27. Learning a foreign language is different than learning other academic subjects.

28. The most important part of learning English is learning how to translate from my native language to English or from English to my native language.

0.56

Factor 4: Learning and communication strategies (Cronbach's alpha $=.90)$

18. It is important to repeat and practice a lot.

7. It is important to speak English with an excellent pronunciation.

13. I enjoy practicing English with the native English speakers I meet.

22. If beginning students are permitted to make errors in English, it will be difficult for them to

26. It is important to practice with cassettes or tapes.

14. It is o.k. to guess if you don't know a word in English.

9. You shouldn't say anything in English until you can say it correctly.

21. I feel timid speaking English with other people

Factor 5 : Motivation and expectations $($ Cronbach's alpha $=.87)$

20. People in my country feel that it is important to speak English.

24. I would like to learn English so that I can get to know native English speakers better and their cultures.

29. If I learn English very well, I will have better opportunities for a good job

31. I want to learn to speak English well.

32. I would like to have friends who speak English as a native language. 
aptitude. Items 1, 2, 5, 6, 10, and 33 deal with the language learning attitude of students' belief, ability, practice, and age. As well, items 35, 11, 16, and 19 deal with disagreement about abilities at learning foreign languages. The second factor, labeled difficulty of language learning, consists of 5 items and represents students' beliefs related to the simplicity level or difficulty of language learning. The third factor, labeled nature of language learning, comprises 6 items and reflects students' attitudes about nature of language learning dealing with the importance of English-speaking cultures and translation. Items of 8, 12, and 28 focus on knowing the culture and forbidding first language translation. The forth factor, labeled learning and communication strategies, comprises 8 items and reflects students' beliefs about practicing English language. The items under communication strategies factor emphasize rehearsals and errors. The fifth factor, labeled motivation and expectations, comprises 5 items and reflects attitudes about better opportunities.

\subsection{Socio-Economic Status Score}

All the variables were scored and the obtained scores were used to clarify different classes. The maximum scores obtained on SES questionnaire by the students were 51, and the minimum score was 5 . Table 3 presents the findings.

Table 3. The relationship between socio-economic status and unemployment

\begin{tabular}{lcccc}
\hline Socio-economic Class & Percent & N & Percent & Unemployed \\
\hline Upper Class & $7.14 \%$ & 25 & $0 \%$ & 0 \\
Upper Middle Class & $20 \%$ & 70 & $2.85 \%$ & 2 \\
Middle Class & $30.86 \%$ & 108 & $27.7 \%$ & 30 \\
Lower Middle Class & $30 \%$ & 105 & $23.8 \%$ & 25 \\
Lower Class & $12 \%$ & 42 & 71.42 & 30 \\
\hline
\end{tabular}

Table 3 shows that 25 students belong to upper class, 70 students are from upper middle class, 108 students are from middle class, 108 students belong to lower middle class, and 42 are from lower class. Thus, the very majority of the students belong to middle class and lower middle class. What is clear about the findings is that 24 percent of unemployed students belong to the lower classes.

\subsection{Socio-Economic Status and BALLI}

The issue of socioeconomic status and its relationship to students' beliefs about language learning is interesting to gain a better understanding of the factors that promote or hinder students' motivation, beliefs, and progress. Table 4 shows the relationship between the participants' socio-economic class and their beliefs about language learning.

Table 4. Relationship between the participants' socio-economic class and their beliefs about language learning

\begin{tabular}{lllllll}
\hline & $\begin{array}{l}\text { Upper } \\
\text { Class }\end{array}$ & $\begin{array}{l}\text { Upper } \\
\text { Class }\end{array}$ & \begin{tabular}{l} 
Middle \\
\cline { 2 - 6 } Foreign Language Aptitude
\end{tabular} & $\begin{array}{l}\text { Middle } \\
\text { Class }\end{array}$ & $\begin{array}{l}\text { Lower } \\
\text { Class }\end{array}$ & $\begin{array}{c}\text { Middle } \\
\text { Lower } \\
\text { Class }\end{array}$ \\
Difficulty of Language Learning & 17 & 35 & 58 & 31 & 18 \\
Nature of Language Learning & 11 & 26 & 79 & 67 & $\mathrm{f}$ & 19 \\
Learning and Communication & 22 & 63 & 62 & 52 & 38 \\
Strategies & & 45 & 89 & 81 & 32 \\
Motivation and expectations & 18 & 45 & & & \\
\hline
\end{tabular}

Table 4 indicates the positions of participants and their beliefs about language learning. The findings in this table shows that all classes paid more attention to factor 4 (learning and communication strategies) and less attention is paid to factor 1 (foreign language aptitude). Factor 2 (difficulty of language learning) and factor 3 (Nature of language learning) deal with problems these classes believe they have about the nature and difficulty of language learning. These factors contain items reflecting students' belief about context, culture, and difficulty of 
language learning. Factor 5 (motivation and expectations) is the second component that is chosen by all classes.

\subsection{Relationship between Socioeconomic Status and Beliefs about Language Learning}

The research question scrutinizes the relationship between socio-economic status and beliefs about language learning. To answer this question, socio-economic status of the students compared with their beliefs about language learning, as shown in Table 4, was examined. The table shows that all classes paid more attention to factor four (learning and communication strategies) and less attention to factor one (foreign language aptitude). Students who belong to different status classes in the context are similar in their beliefs about language learning. The view of beliefs is supported by the fact that these results are obtained from different socio-economic classes. This emphasis on beliefs is notable suggesting that there is room for further research in this particular orientation. The findings reflected that students' beliefs and perceptions related to the process of language learning have been connected to their socio-economic status as well. Thus, the findings of this study are in line with previous studies in that socio-economic can create differential treatment with learners on the basis of their economy (Ogunshola \& Adewale, 2012; Rothman, 2003).

\section{Conclusion}

The purpose of this study was to investigate the relationship between socio-economic status of Iranian postgraduate students and their language learning beliefs. In fact, understanding language learners, their needs, and challenges may lead to learning success. Based on the findings of this study, factors that promote foreign language learning are twofold: socio-economic status and a genuine interest and belief in learning a foreign language. Factors that discourage foreign language learners from effective learning are probably related to debilitating beliefs, which are concerned with social and economic statuses as well as language learning interests and motivation. Hence, it is important for language teachers to generate positive attitudes in their students toward language learning regardless of probable intervening debilitating factors. Among the wide variety of factors that influence foreign language learners' beliefs, this study explored the effect of socio-economic status of learners on their language learning beliefs. The findings demonstrated that socio-economic status can have significant effects on learners' beliefs toward language learning. Socio-economic status can encourage or discourage learners. The findings have some implications for language teachers in that they help language learners adapt to the difficulties and improve their situations. The main message is that teachers become aware of learners' tribulations regarding learning based on their different social levels. Responsible teachers are aware that their behaviors have a deep impression on language learners because their students trust them implicitly. One way to attract all learners is to diagnose learners' interest and belief in learning a foreign language. Awareness of learners' interests makes teachers analyze them in a new light. In general, the findings of the present study help language teachers to pay serious attention to psychosocial dimensions of language learners' beliefs about language learning and their socio-economic status. Understanding and recognizing learners' social status, their priorities, and existing conditions enable teachers to create better supportive learning environment and to provide necessary educational facilities for effective learning.

\section{References}

Ajzen, I. (1988). Attitudes, personality, and behavior. Chicago: Dorsey Press.

Altan, M. Z. (2012). Pre-service EFL teachers' beliefs about foreign language learning. European Journal of Teacher Education, 35(4), 481-493. http://dx.doi.org/10.1080/02619768.2011.643399

Arnold, J. (1999). Affect in language learning. Cambridge: Cambridge University Press.

Babikkoi, M. A., \& Binti Abdul Razak, N. Z. (2014). Implications of parents' socio-economic status in the choice of English language learning strategies among Nigeria's secondary school students. English Language Teaching, 7(8).

Benson, P. (2001). Teaching and researching autonomy in language learning. Harlow: Pearson Education Limited.

Benson, P. (2007). Autonomy in language teaching and learning. Lang. Teach, 40, 21-40. http://dx.doi.org/10.1017/S0261444806003958

Barcelos, A. M. F., \& Kalaja, P. (2003). Conclusion: Exploring possibilities for future research on beliefs about SLA. In P. Kalaja \& A. M. F. Barcelos (Eds.), Beliefs about SLA: New research approaches (pp. 231-238). Boston: Kluwer Academic Publishers.

Breen, M. P. (Ed.). (2001). Learner contributions to language learning: New directions in research. Harlow, Essex: Pearson Education Limited. 
Carr, J., \& Pauwels, A. (2006). Boys and foreign language learning: Real boys don't do languages, Basingstoke: Palgrave Macmillan

Coleman, J. S. (1966). Equality of educational opportunity (Report No. OE-3800). Washington, DC: National Center for Educational Statistics

Cotterall, L. S. (1995). Readiness for autonomy: Investigating learner beliefs. System, 23(2), 195-205. http://dx.doi.org/10.1016/0346-251X (95)00008-8

Demmert, W. G., Jr. (1993). Language, learning and national goals: A Native American view. The issues of language and culture: Proceedings of a symposium. Washington, CD: Center for Applied Linguistics.

Dong, J. (2011). Discourse, identity, and china's internal migration: The long march to the city. Bristol, U.K.: Multilingual Matters.

Dörnyei, Z. (2005). The psychology of the language learner: Individual differences in second language acquisition: Lawrence N. J. Lawrence Erlbaum Associates.

Fan, W. (2011). Social influences, school motivation and gender differences: An application of the expectancy-value theory. Educ. Psychol. Rev, 31, http://dx.doi.org/10.1080/01443410.2010.536525

Fishbein, M., \& Ajzen, I. (1975). Belief, attitude, intention and behavior: An introduction to theory and research. Reading, MA: Addison-Wesley.

Fonseka, E. A. G. (2003). Autonomy in a resource-poor setting: enhancing the Carnivalesque. In D. Palfreyman \& R. C. Smith (Eds.), Learner autonomy across cultures: Language education perspectives (pp. 163-147). Palgrave Macmillan, Basingstoke.

Gayton, A. (2010). Socioeconomic status and language-learning motivation: To what extent does the former influence the latter? Scottish Languages Review, 22, 17-28.

Graham, C. R., \& Brown, C. (1996). The effects of acculturation on second language proficiency in a community with a two-way bilingual program. Bilingual Research Journal, 20, 235-260. http://dx.doi.org/10.1080/15235882.1996.10668629

Hannum, E., Park, H., \& Butler, Y. G. (2010). Globalization, changing demographics, and educational challenges in East Asia. Bingley, U.K.: Emerald. http://dx.doi.org/10.1108/S1479-3539 (2010)17

Horwitz, E. K. (1987). Surveying student beliefs about language learning. In A. Wenden \& J. Rubin (Eds.), Learner strategies in language learning (pp.119-129). London: Prentice-Hall.

Horwitz, E. K. (1988). The beliefs about language learning of beginning university foreign language students. Modern Language Journal, 72, 283-293. http://dx.doi.org/10.1111/j.1540-4781.1988.tb04190.x

Horwitz, E. (2007). Becoming a language teacher: A practical guide to second language learning and teaching. Hong Kong: Pearson.

Jernigan, C. G. (2001). The role of beliefs, attributions, and perceived goal attainment in students' motivation. In G. Bräuer (Ed.), Pedagogy of language learning in higher education (pp. 23-45). Westport, CT: Ablex

Kern, R. G. (1995). Students' beliefs and teachers' beliefs about language learning. Foreign Language Annals, 28, 71-92. http://dx.doi.org/10.1111/j.1944-9720.1995.tb00770.x

Kormos, J., \& Csizér, K. (2008). Age-related differences in the motivation of learning language attitudes and language learning motivation. Journal of Language and Social Psychology, 24, 1-31. http://dx.doi.org/10.1016/j.system.2013.03.006

Kormos, J., \& Kiddle, T. (2013). The role of socio-economic factors in motivation to learn English as a foreign language: The case of Chile. System, 41, 399-412. http://dx.doi.org/10.1016/j.system.2013.03.006

Lamb, M. (2012). A self-system perspective on young adolescents' motivation to learn English in rural and urban settings. Lang. Learn, 62, 997-1023. http://dx.doi.org/10.1111/j.1467-9922.2012.00719.x

Majoribanks, K. (1996). Family learning environments and students outcomes: A review. Journal of Comparative Family Studies, 27(2), 373-394.

Mantle-Bromley, C. (1995). Positive attitudes and realistic beliefs: Links to proficiency. Modern Language Journal, 79(3), 372-386. http://dx.doi.org/10.1111/j.1540-4781.1995.tb01114.x

Martin, I. (1990). Vocabulary acquisition in a content-based approach. Guidelines, 12(2), 1-11.

Miele, P. (1982). Suggestopedia: Easier learning the natural way. Sandy Spring, MD: Utopia Unlimited. 
Nikitina, L., \& Furuoka, F. (2006). Re-examining of Horwitz's beliefs about language learning Inventory (BALLI) in the Malaysian context. Electronic Journal of Foreign Language Teaching, 3(2), 209-219.

Norton, B., \& Toohey, K. (2001). Changing perspectives on good language learners. TESOL Quarterly, 35 , 307-322. http://dx.doi.org/10.2307/3587650

Nyikos, M., \& Oxford, R. (1993). A factor analytic study of language learning strategy use: Interpretations from information processing theory and social psychology. Modern Language Journal, 77(1), 11-22. http://dx.doi.org/10.1111/j.1540-4781.1993.tb01940.x

Ogunshola, F., \& Adewale, A. M. (2012). The Effects of Parental Socio-Economic Status on Academic Performance of Students in Selected Schools in EduLga of Kwara State Nigeria. International Journal of Academic Research in Business and Social Sciences, 2(7).

Parson, R. D., Hinson, S. L., \& Sardo-Brown, D. (2001). Educational psychology: A practitioner- researcher. Model of Teaching. Singapore: Thomson Learning Inc.

Peacock, M. (2001). Preservice ESL teachers' beliefs about second language learning. A longitudinal study. System, 29, 177-195. http://dx.doi.org/10.1016/S0346-251X (01)00010-0

Pennycook, A. (1994). The cultural politics of English as an international language. London: Longman.

Rad, N. (2010). Evaluation of English Students' Beliefs about Learning English as Foreign Language: A Case of Kerman Azad University. Proceedings of ICT for Language Learning Conference (3rd Edition), Simonelli Editore.

Rifkin, B. (2000). Revisiting beliefs about foreign language learning. Foreign Language Annals, 33, $394-420$. http://dx.doi.org/10.1111/j.1944-9720.2000.tb00621.x

Rothman. S. (2003). The changing influence of socioeconomic status on student achievement: Recent evidence from Australia. Paper presented at the annual meeting of the American Educational Research Association (pp. 21-25), Chicago.

Sakui, K., \& Gaies, S. J. (1999). Investigating Japanese learners' beliefs about language learning. System, 27 , 473-492. http://dx.doi.org/10.1016/S0346-251X (99)00046-9

Strevens, P. (1978). The nature of language teaching. In R. C. Richards (Ed.), Understanding second and foreign language learning: Issues and approaches (pp. 179-203). Rowley: Newbury House.

Turner, P. R. (1974). Why Johnny doesn't want to learn a foreign language. Modern Language Journal, 58, 155-196. http://dx.doi.org/10.1111/j.1540-4781.1974.tb05096.x

\section{Copyrights}

Copyright for this article is retained by the author(s), with first publication rights granted to the journal.

This is an open-access article distributed under the terms and conditions of the Creative Commons Attribution license (http://creativecommons.org/licenses/by/3.0/). 